\title{
Universidade - Núcleos temáticos: em busca da indissociabilidade ensino-pesquisa-extensão
}

\author{
Paulo Vinicius Baptista da Silva \\ Acácia Zeneida Kuenzer
}

\begin{abstract}
RESUMO
A partir dos pressupostos de CHAUÍ sobre a organização social brasileira e a inserção social da Universidade em seu tecido social oligárquico, autoritário e violento, o texto discute o princípio da indissociabilidade ensino-pesquisaextensão como forma de ação crítica e modificadora. Apresenta a proposição do Setor de Educação da UFPR de organização em Núcleos Temáticos como forma de responder organicamente às demandas sociais. Dentro dos princípios arrolados para tais, descreve pontos da ação e trajetória do Núcleo de Estudos Interdisciplinares sobre a Criança e o Adolescente/ NEICA, seus pressupostos e objetivos.

Palavras-chave: indissociabilidade ensino-pesquisa-extensão, Universidade, infância e adolescência.
\end{abstract}

\begin{abstract}
From Chaui's pressuppositions about Brazilian social organizatioon and its social insertion in the University in its function as social oligarchy, authoritarian and violent, the principle of inseparable teaching-research-continuing education as a critical and modifying action is discussed. The School of Education of the Federal University of Parana proposition about a way of organizing thematic issues as an organically reply to social demand is presented. According to principles set for such purpose , action and strategies of the Nucleus of Interdisciplinary Studies about Children and Teenagers /NEICA, its pressupositions and goals are described.

Key-words: inseparable teaching-research-continuing education, University, children and teenagers.
\end{abstract}

\section{Introdução}

Em artigo que discute a relação entre Ética e Universidade, CHAUí (1995) aponta alguns traços da sociedade brasileira: relações sociais altamente hierarquizadas, determinando a discriminação em diversos âmbitos; relações sociais e políticas fundadas em contatos pessoais, favorecendo a relação sociopolítica do favor, a clientela e a tutela; desigualdades econômicas extremas, levando à polarização entre a carência e o privilégio; e a lei não opera como lei, opera como repressão do lado dos carentes e como conservação de privilégios do lado dos dominantes.

A autora segue descrevendo a forma de inserção da Universidade nesse tecido social oligárquico, autoritário e violento: 1- Tem aceitado passivamente a destruição do ensino público de $1 .^{\circ}$ e $2 .^{\circ}$ Graus, a privatização, o aumento das desigualdades sociais. 2- Os docentes mantêm reivindicações de caráter corporativista, seguindo outras categorias. 3- Tendência a aceitar cada vez mais a separação entre docência e pesquisa, e entre graduação e pós-graduação. 4- Aceitação acrítica do modo de criação de Universidades Federais, para servir a interesses oligárquicos locais. 5- Império da ausência de: carreiras definidas, concursos públicos transparentes, clareza de funções, formação e atualização de funcionários, atualização dos procedimentos administrativos. 6- Aceitação acrítica da privatização das pesquisas. O financiamento privado traz: a) perda da autonomia para definir prioridades, conteúdos, formas etc.; b) aceitação de que o estado não é responsável pelo financiamento; c) privatização via complementação salarial; d) desprestígio crescente das humanidades; e) aceitação dos parcos vencimentos. De tal forma, nas universidades públicas imperam elementos contrários à ética, definida como recusa da violência, orientadora da idéia da igualdade, da justiça, do acesso à liberdade e à democracia. Feitas estas considerações, CHAUí $(1995$, p. 87) encerra com uma provocação: “que tal reconstruirmos a Universidade Pública?”.

Para uma reflexão sobre tal indagação é preciso se defrontar com o processo de estruturação da Universidade no Brasil. Dentre os pontos levantados, dois parecem de vital importância; a indissociabilidade 
entre ensino, pesquisa e extensão e o financiamento privado da pesquisa. O princípio da indissociabilidade entre as três funções pouco tem se concretizado na prática acadêmica, embora incorporada nos estatutos das Universidades, como explicitado por MAZZILI (1996):

De fato, a estrutura departamental favorece o desenvolvimento de ações individuais voltadas para dentro da própria universidade. $\mathrm{O}$ ensino não tem fugido muito da tradição de reprodução do conhecimento. Na verdade, quanto mais qualificado um docente, mais ele tende a se afastar da sala de aula, especialmente da graduação, para dedicar-se à pós-graduação e à pesquisa. Os projetos de extensão, quando existem, ficam em geral descolados. A estrutura departamental favorece o desenvolvimento de ações individuais estruturalmente, como se fosse de interesse e responsabilidade exclusiva de seus autores.

Portanto, o princípio da indissociabilidade é muito mais uma proposição ou uma meta a ser alcançada. Sua inclusão na Constituição é fruto da participação da sociedade civil organizada, particularmente do "Fórum Nacional em Defesa da Escola Pública", sendo "uma das expressões do conflito entre as diferentes forças sociais que atuaram durante a constituinte” (MAZZILI, 1996, p. 7). Neste ponto em específico, não é caso de reconstruir, mas de buscar caminhos para a efetivação do princípio.

Algumas tentativas têm sido levadas a termo pelo Setor de Educação da Universidade Federal do Paraná via a organização de Núcleos Temáticos. A partir de um diagnóstico junto aos diferentes departamentos do Setor de Educação, constatou-se a necessidade da articulação efetiva entre ensino, pesquisa e extensão, que na prática continuavam como ações isoladas; a desarticulação entre a graduação e a pósgraduação com a quase inexistência de relação entre a pesquisa produzida neste último nível e a pesquisa, o ensino e a extensão que transcorrem na graduação; e o desenvolvimento de projetos individuais (mesmo quando envolviam alunos), com uma certa fragmentação e desarticulação das ações, decorrentes da departamentalização, não havendo espaço para a discussão das divergências. A partir deste diagnóstico formulou-se a concepção de núcleo temático como alternativa de superação da fragmentação e do isolamento do mundo das relações concretas em busca da organicidade, nos níveis interno e externo, e como estratégia de articulação entre ensino, pesquisa e extensão, permitindo assim a integração entre graduação e pós-graduação.

Para tanto, contrariando a concepção dominante que faz do núcleo temático a articulação de pesquisadores em torno de um tema específico dentro de uma linha de pesquisa, o Setor de Educação da UFPR construiu seus núcleos temáticos através dos princípios enunciados a seguir:

- os núcleos temáticos se organizam a partir de demandas das relações sociais e produtivas: das instituições de ensino e de administração da educação, do sistema produtivo, das agências de formação profissional e de promoção de emprego, dos movimentos sociais organizados, entidades de classe, sindicatos etc.

- os núcleos temáticos se organizam a partir de um corpo epistemológico próprio, determinado pela natureza do seu objetivo; este corpo epistemológico constitui-se dos conhecimentos básicos que são necessários para compreender o objeto e formular o projeto para enfrentá-lo;

- os núcleos temáticos exigem abordagem transdisciplinar, uma vez que seus objetos, ao se derivarem da prática social, apresentam-se multifacetados e desta forma não podem ser apreendidos por abordagens específicas de cada área do conhecimento; esta nova abordagem não é apenas a " juntada" de várias áreas específicas, mas a construção de um conhecimento novo, síntese superadora de conhecimentos parciais e, em decorrência, sua transformação; é essa abordagem que constrói o corpo epistemológico próprio de cada núcleo;

os núcleos temáticos exigem abordagens interinstitucionais, por seu caráter transdisciplinar, derrubando as barreiras internas entre os cursos de graduação e de pós-graduação, entre os departamentos, entre as faculdades/centros/institutos; derrubando as barreiras externas, integrando profissionais interessados no estudo do objeto do núcleo ou atuantes nas escolas, no poder público das diferentes instâncias, nas entidades, nos movimentos sociais organizados; desta forma, através do núcleo temático articulam-se as mais diferentes instituições e as mais diferentes experiências teórico-práticas, permitindo uma efetiva integração de esforços voltada para compreensão, para a produção do conhecimento, para a sua divulgação e para a melhoria da qualidade de ensino, tendo em vista a transformação da realidade que se constitui em objeto do núcleo; neste sentido, o núcleo temático é o espaço da práxis.

Com base nestes princípios, foi criado o Núcleo de Estudos Interdisciplinares sobre a Criança e o Adolescente/NEICA, que teve início em abril de 1995, sob o nome de Núcleo de Educação da Criança e do Adolescente em Situação de Risco. Sua origem remonta a 1994, quando profissionais do setor público procuraram o Setor de Educação para solicitar apoio na discussão dos programas ofertados a crianças e 
adolescentes em situação de risco. A partir dessa demanda, passa-se a realizar, de forma mais sistemática, reuniões sobre as possíveis parcerias e contribuições da Universidade, tendo em vista a compreensão e o enfrentamento da situação das crianças e adolescentes menos favorecidos em nosso meio social, culminando com a criação do Núcleo segundo a concepção de núcleos temáticos adotada pelo Setor de Educação.

O NEICA tem como objetivo constituir um centro de referência na UFPR para estudos Interdisciplinares da criança e do adolescente, que tenha como prioridade a busca de respostas para os problemas que a população infanto-juvenil enfrenta na sociedade brasileira para seu pleno desenvolvimento. Para tal, visa produzir e difundir conhecimentos na área de estudo e promover intercâmbio de informações. As temáticas de pesquisa selecionadas são: 1) Políticas Públicas, Legislação e Sociedade Civil. 2)Programas de Educação Formal, Não Formal e Informal. 3) Desenvolvimento Psicossocial e Condições de Vida da Infância e da Adolescência na Sociedade Brasileira. 4)Trabalho e Formação Profissional.

Os artigos apresentados representam parte do processo de estruturação do NEICA, e de sua articulação com outros centros. Este Núcleo tem promovido uma série de atividades; projetos e programas de extensão, projetos de pesquisa, eventos e cursos de especialização, qualificação e atualização, intercâmbios, assessorias, palestras e conferências. Os temas dos artigos dispostos a seguir ficam circunscritos às temáticas acima listadas.

Nos estudos e projetos levados a termo pelo NEICA, aparece bem delineada a organicidade entre pesquisa e extensão. A comunicação com a comunidade foi uma constante, sendo que a maior parte das iniciativas partiu de demandas propostas. Em geral utilizou-se uma metodologia participativa e os resultados alcançados geraram ações decorrentes. Em relação às atividades de ensino, avalia-se que o nível de integração esteja aquém do desejado. A participação de acadêmicos(as) nos projetos tem sido em proporção menor que a necessária e por vezes pontual, como também as relações com conteúdos de disciplinas ofertadas aos cursos de graduação.

Outro ponto que se busca atingir e que está em parte contemplado é a interdisciplinaridade. É preciso lembrar que esta é sempre um devir, nunca está determinada por um plano ou projeto. Estes contêm uma perspectiva multidisciplinar, de organicidade entre áreas diferentes de conhecimento com vistas a tratar de fenômenos complexos. A interdisciplinaridade será atingida se a cooperação entre as áreas chegar a uma construção de novos conceitos, que não são exclusivos de nenhuma das áreas (JAPIASSU, 1976). Analisando os resultados de estudos e projetos realizados, depara-se com elementos que permitem classificá-los como interdisciplinares conceitualmente ou contextualmente (revitalização de conceitos ao serem aplicados a novos contextos).

Sobre o tema do financiamento privado, é nítido que as pesquisas relacionadas a temas sociais urgentes são as que mais sofrem. Na medida que o Estado se esquiva da função de financiamento, o setor privado naturalmente não assume o que não vá de encontro aos seus interesses. Lembrando que o desenvolvimento está ancorado na produção de conhecimentos, haverá um quadro de agravamento da dívida social. De fato, é o que se assiste em mais uma década perdida, que sucede a anterior.

Do ponto de vista das políticas para a infância, vislumbram-se alguns avanços a partir do advento do Estatuto da Criança e Adolescente, mas tímidos se considerarmos a proposição de RIZZINI(1998), de que este foi um "século perdido" para as políticas relacionadas à infância.

Neste quadro de mudança de paradigma sobre a infância e adolescência são vitais as informações sobre o mais fidedignas e difundidas possíveis, pois vive-se embate contra a ideologia pós-moderna que apregoa um individualismo extremo e uma indiferença generalizada em face dos fatos sociais. O conhecimento sistemático pode possibilitar uma inserção crítica e contextualizada, de modo a promover o respeito aos direitos e a superação de um Estado de "cidadania negativa", "acidadania" ou "descidadania", no qual se substitui o direito retórico pelo direito alterativo (SEDA,1995).

A relação de trocas com a sociedade civil organizada, particularmente com os movimentos reivindicatórios de direitos, é ponto vital para que a prática de pesquisa-ensino-extensão esteja em conformidade com a ética proposta por CHAUÍ.

Sob estes princípios leva-se a termo esta proposta de "reconstrução da Universidade", muitas vezes com um sentimento de Sísifo, mas com a busca autêntica de construir um lugar melhor, ou como proposto por Lígia C. Leite no artigo a seguir, imaginando Sísifo feliz. 


\section{REFERÊNCIAS}

CHAUÍ, M. Ética e universidade. In: . Universidade e Sociedade. Brasília: Andes, 8 fev. 1995. p. 82-87.

JAPIASSU, H. Interdisciplinaridade e patologia do saber. Rio de Janeiro: Imago, 1976.

MAZZILI, S. Notas sobre indissociabilidade entre ensino-pesquisa-extensão. In: Brasília: Andes, 11 jun. 1996. p. 4-10.

RIZZINI, I. O Século Perdido. Rio de Janeiro: Amais, 1998.

SEDA, E. A Criança e o Direito Alterativo. Campinas: Adês, 1995. 